\title{
Successful repeat percutaneous transluminal coronary angioplasty after failed coronary artery surgery for left main coronary artery dissection
}

\author{
DAVID R RAMSDALE, PETER M SCHOFIELD
}

From the Regional Adult Cardiothoracic Unit, Broadgreen Hospital, Liverpool

SUMMARY A 57 year old man required emergency coronary artery bypass surgery after dissection of the left main coronary artery during percutaneous transluminal coronary angioplasty. His symptoms recurred when the vein grafts became occluded. A dilatation device with the lowes: profile was used to reduce the need for firm support from the guiding catheter during repeae percutaneous transluminal coronary angioplasty. The repeat procedure was successful in opening up the left circumflex coronary artery.

Dissection of the left main coronary artery is a well recognised but uncommon complication of coronary angiography and percutaneous transluminal coronary angioplasty that requires emergency coronary

Requests for reprints to Dr David R Ramsdale, Regional Adult Cardiothoracic Unit, Broadgreen Hospital, Thomas Drive, Liverpool L14 3LB. artery bypass surgery. ${ }^{1}$ Dissection can occur wher the guiding catheter is deeply engaged in the coron $\overline{0}$ ary artery in order to provide support so that the balloon catheter can be advanced across a high grade stenosis during angioplasty.

We describe a patient in whom coronary bypass surgery performed for this complication subsequene
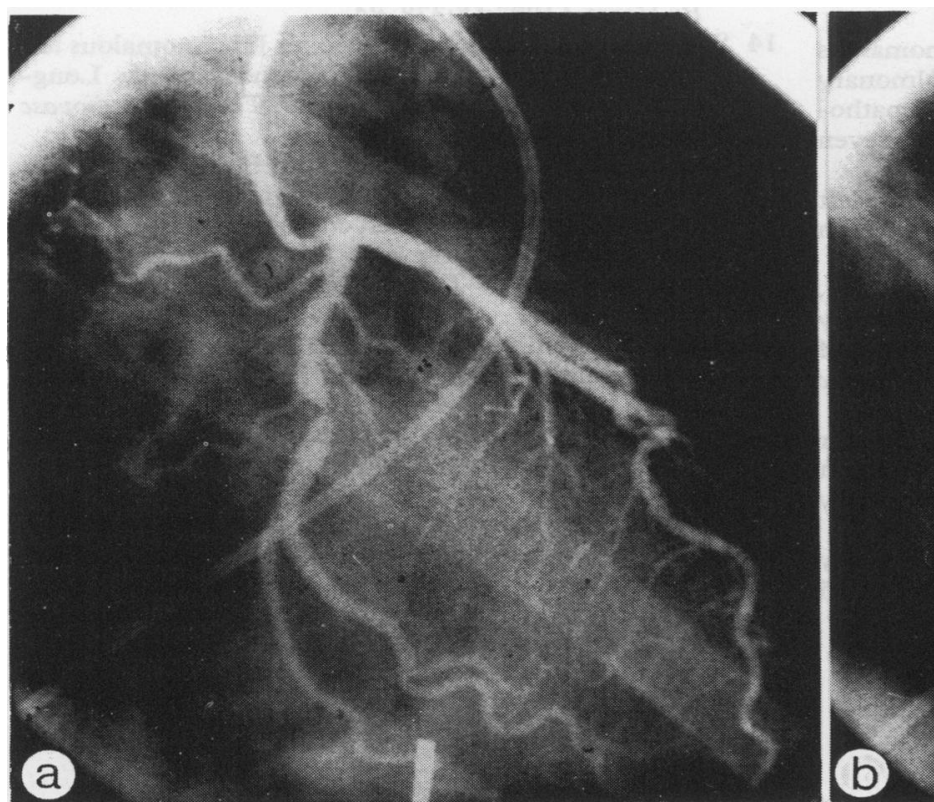

Fig 1 Angiogram in the right anterior oblique projection showing (a) a severe stenosis in the circumflex artery before coronary angioplasty. (b) During the procedure dissection of the left main coronary artery occurred (arrow). 


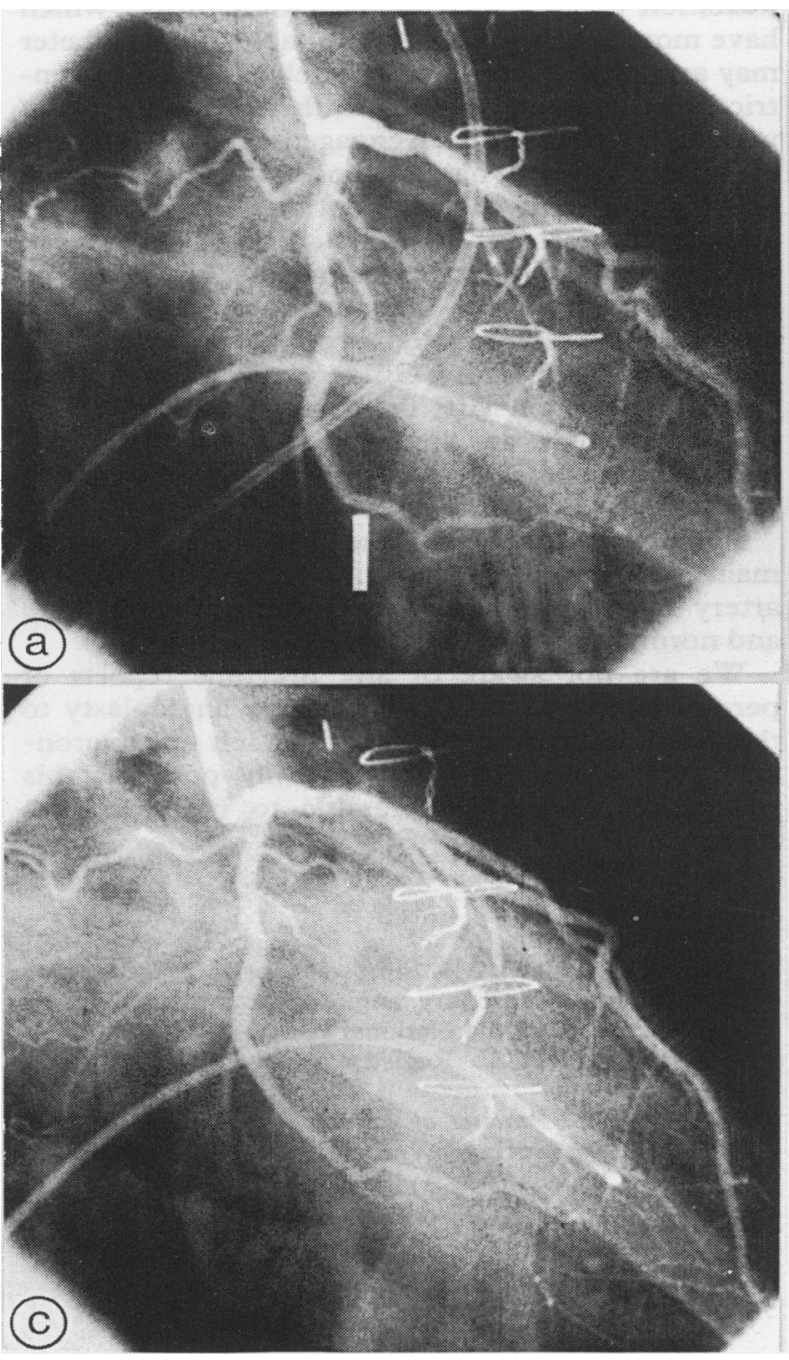

tly failed but where repeat percutaneous transluminal coronary angioplasty using the lowest profile dilatation device was successful.

\section{Case report}

A 57 year old man with a twelve month history of severe angina was found to have an eccentric stenosis of $95 \%$ of the diameter of the mid-third of a dominant left circumflex coronary artery (fig 1a). During coronary angioplasty, it was difficult to advance a $3.0 \mathrm{~mm}$ low profile "snake" balloon dilatation catheter (balloon profile (BP) $1.3 \mathrm{~mm}$ ) acoss the stenosis. An attempt to obtain more support for the balloon catheter by deeply engaging an $8 \mathrm{~F}$

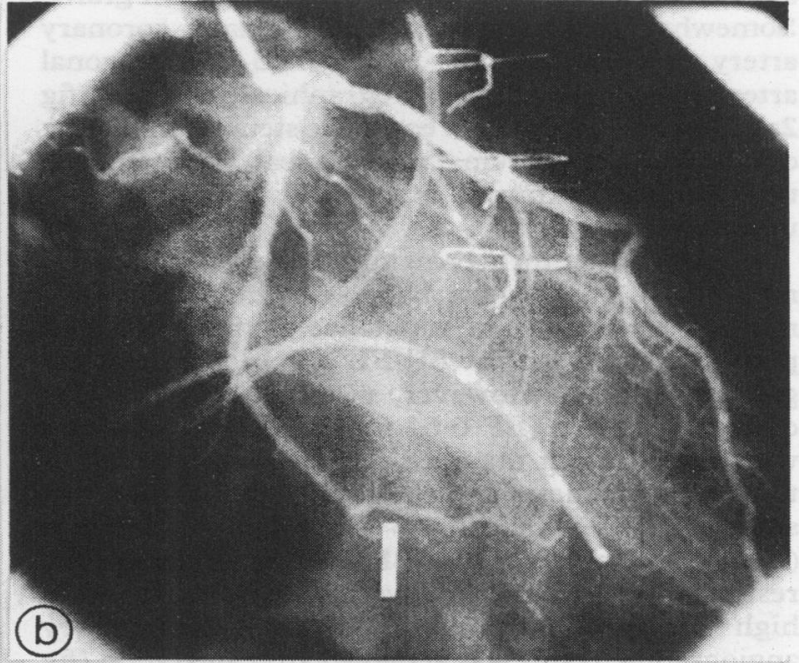

Fig 2 Repeat angiograms in the right anterior oblique projection showing (a) the normal appearance of the left main and left anterior descending arteries and an unchanged stenosis in the circumflex artery. (b) After dilatation with a $2.5 \mathrm{~mm}$ probe and subsequently a $3.0 \mathrm{~mm}$ balloon catheter, $a$ satisfactory angiographic result was obtained. (c) Eight months later there was no evidence of important restenosis.

Amplatz soft-tip guiding catheter caused dissection of the left main coronary artery (fig 1b). This rapidly progressed to cause subtotal occlusion of the left coronary artery, chest pain, and anterior ST segment elevation. The patient underwent emergency coronary artery bypass grafting to the left anterior descending, first diagonal, and first and second obtuse marginal coronary arteries.

Within three months of operation, however, he again began to experience angina on moderate effort and subsequently his symptoms increased in frequency and severity despite full medical treatment.

Thirteen months after the operation the patient underwent repeat coronary angiography. This 
showed occlusion of all of the saphenous vein grafts. Somewhat surprisingly, the left main coronary artery, left anterior descending, and first diagonal arteries appeared to be angiographically normal (fig 2a). However, the severe eccentric stenosis in the left circumflex artery remained. Repeat percutaneous transluminal coronary angioplasty was therefore undertaken.

A further attempt at crossing the stenosis with a 2.5 mm USCI profile plus balloon catheter (BP 0.91 $\mathrm{mm}$ ) failed because of resistance at the lesion and poor support from the $8 F$ FL 3.5 Judkins soft tip guiding catheter. However, a $2.5 \mathrm{~mm}$ USCI probe dilatation device (BP $0.64 \mathrm{~mm}$ ) crossed the lesion with ease without the need for deep engagement of the guiding catheter and a satisfactory dilatation was achieved. We advanced a $3.0 \mathrm{~mm}$ balloon catheter (USCI low profile plus, BP $0.97 \mathrm{~mm}$ ) across the residual lesion using a conventional $0.36 \mathrm{~mm}$ ACS high torque floppy guide wire. A satisfactory angiographic result was achieved after dilatation (fig 2b).

The patient was active and free of angina six months later. At eight months there was no angiographic evidence of restenosis (fig 2c).

\section{Discussion}

Dissection is more likely to occur with $9 \mathrm{~F}$ Judkins and with Amplatz shaped guiding catheters. ${ }^{2}$ Soft tipped catheters have been produced to help minimise the risk but they are unlikely to eliminate this complication completely. Moreover, this case highlights the advantage of the extremely low profile of dilatation devices such as the USCI probe, which have more recently become available. This cathetec may assist safe crossing of severely stenosed, eccen tric lesions situated distally in the coronary arteries without the need for deep engagement of the guiding catheter. However, having chosen this catheter, the operator currently has to accept that unless the raties of balloon:vessel size is optimal, the lesion may nee 8 to be recrossed to improve the final angiographig result-a procedure that still causes concerf especially when intimal dissection is visible. The SciMed DGW (Dilating Guide Wire - with a $1.5 \mathrm{~mm}$ polyolefin balloon (BP $0.43 \mathrm{~mm}$ )), which can b passed through an appropriately sized TRAC? balloon catheter, is designed to help overcome this problem.

Finally, our case shows one possible course of lefr? main coronary artery dissection treated by coronar artery bypass surgery-that is subsequent healing and normalisation of the vessel.

We are not aware of any previous reports of percutaneous transluminal coronary angioplasty to the native left coronary artery after left main coron $₫$ ary artery dissection. If technically possible, thi쿙 procedure is clearly preferable to repeat bypas surgery.

\section{References}

1 Dorros G, Cowley MJ, Simpson J, et al. Percutaneou transluminal coronary angioplasty: report of com를 plications from the National Heart, Lung and Blood Institute PTCA Registry. Circulation 1983;6 \% 723-30.

2 Ischinger T. Practice of coronary angioplasty. Berlin $\overrightarrow{\vec{b}}$ Heidelberg: Springer Verlag, 1986:135, 148, 252. 